\title{
SUPPORT OF KNOWLEDGE CREATION PROCESSES IN A COMPUTER-BASED COLLABORATIVE SYSTEM
}

\author{
Ján Paralič, František Babič \\ Centre for Information Technologies, Technical University of Košice, Slovakia, \\ \{jan.paralic, frantisek.babic\}@tuke.sk
}

\begin{abstract}
This paper presents a particular approach how to support the knowledge creation processes that are based on innovative idea of trialogical learning. The key task in trialogical learning is to understand how the "weaker" forms of knowledge are used and made explicit in a meaningful way in collaborative processes. Trialogical learning provides mechanism by which tacit knowledge is conceptualized in collaborative systems. Within the "Knowledge-Practices Laboratory" (KP-Lab) ${ }^{l}$ project suitable tools and practices for support of trialogical learning are being designed, implemented and evaluated. The KP-LAB platform offers, except of others, also facilities for discovering, managing and visualization of some tacit knowledge. We present in this paper one particular approach how to this is supported with proposed awareness features
\end{abstract}

\section{INTRODUCTION}

One important aspect of collaborative systems (virtual learning environments, computerbased collaborative systems, etc.) is awareness support that provides information about performed activities, about user's behavior, relations between participants or between participants and environment, reasons of decisions, etc. This information is can be viewed as a kind of tacit knowledge that could be expressed and used for identification of innovative ideas and re-use it in future processes.

Tacit knowledge are described as knowledge that people carry in their minds and therefore it is difficult to access. Tacit knowledge is regarded more valuable because it provides context for situations, ideas or experiences. This concept is widely used in various disciplines, such as knowledge management, artificial intelligence and psychology. In the field of knowledge-based systems researchers have been, in the last decades, mainly concerned about making (some) tacit knowledge explicit.

In the field of knowledge management, Nonaka and Takeuchi (Nonaka and Takeuchi, 1995) introduced a paradigm shift by developing a practical aspect of tacit knowledge. This approach considers tacit knowledge as non-linguistic non-numerical form of knowledge that is highly personal, context specific and deeply rooted in individual experiences, ideas, values and emotions. This approach suggests that tacit knowledge has to be captured and communicated in organisations in order to enhance knowledge creation processes.

Nonaka and Takeuchi's work as well as other two theoretical approaches to knowledge creation are briefly described in the following section 2 , together with

\footnotetext{
${ }^{1}$ www.kp-lab.org
} 
a generalized view of knowledge creation as a trialogical learning process and a way how this approach is followed within the KP-Lab project from the technological perspective. Section 3 focuses on one important aspect of the KP-Lab technological platform, namely awareness support that in our opinion provides a kind of tools supporting both, tacit knowledge capture and reuse, as well as support of collaborative knowledge creation processes as such.

\section{KNOWLEDGE CREATION}

Knowledge creation is one of the core aspects of trialogical learning and of the knowledge development in general (this includes also knowledge adoption, distribution, review and revision) within an organization. From the methodological point of view the knowledge creation processes have been studied in different contexts (Paavola et al., 2004):

- Carl Bereiter's knowledge building approach has emerged from cognitive studies in the educational context (Bereiter and Scardamalia, 1993),

- Yrjö Engeström's theory of expansive learning is based on Activity Theory (Engeström, 1999), and

- Nonaka and Takeuchi's model of organizational knowledge creation originates from the analysis of work in Japanese companies (Nonaka and Takeuchi, 1995).

Tacit knowledge can be seen as an important aspect of these models although with different interpretation in particular approaches:

- Bereiter emphasizes conceptual artefacts and ideas which are collaboratively developed,

- Engeström emphasizes practices and activities which are reflected and transformed in collective processes, and

- Nonaka \& Takeuchi emphasize personal hunches and insights which are explicated for the use of the community.

Tacit knowledge are based on the idea that knowledge is not something expressed in symbolic or declarative means but on various other meanings, signs, and structures embedded in visual representations, practices, concrete artefacts, diagrams, etc. The key task for trialogical learning is to understand how these "weaker" forms of knowledge are used and made explicit in a meaningful way in collaborative processes.

\subsection{Trialogical learning}

Trialogical learning is a relative new approach in CSCL (Computer-supported Collaborative Learning) and CSCW (Computer-supported Cooperative Work) domain. Theoretical as well as practical aspects of this innovative approach started to be researched and developed in Finland, at the University in Helsinki. From this institution the idea is being distributed now in the (not only) European educational community, e.g. within the Knowledge Practices Laboratory (KP-Lab) project.

Trialogical learning has emerged from the theories that are mentioned thereinbefore. Trialogical learning is not supposed to be a "super-theory" on the basis of these background theories but it pinpoints certain kinds of phenomena which are prevalent and central nowadays: how people organize their work for developing some shared, concrete "objects" (like conceptual artefacts, practices, products), see Figure 1. 


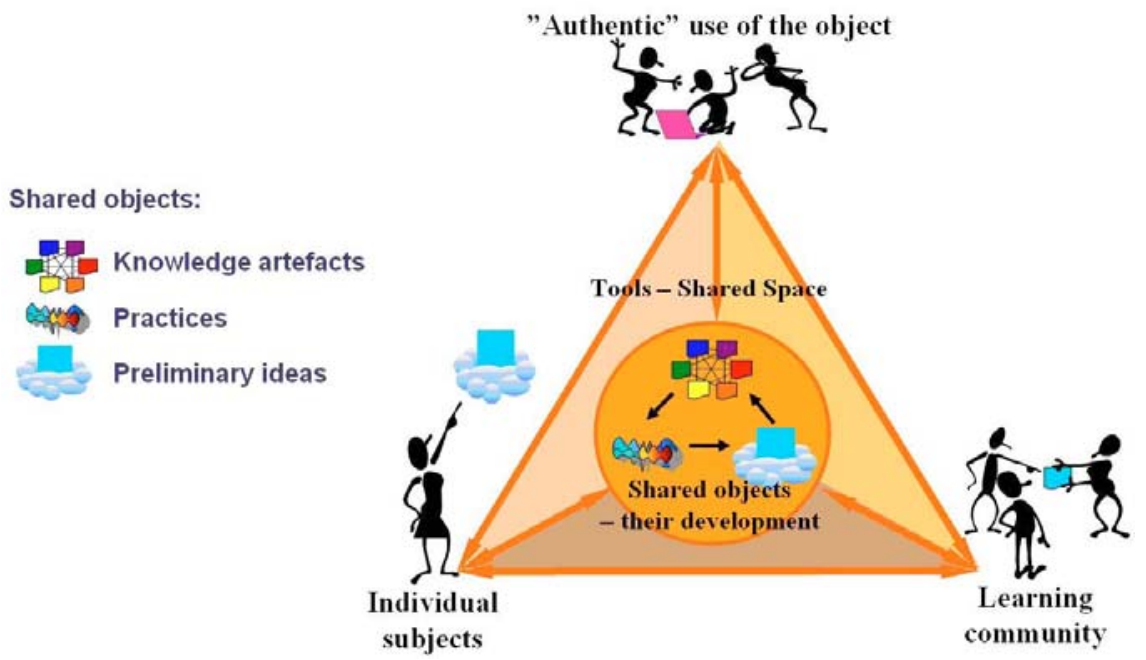

Figure1. Trialogical approach (Paavola et al., 2004)

Trialogical learning (Hakkarainen and Paavola, 2007) refers to the process where learners are collaboratively developing shared objects of activity in systematic fashion. It concentrates on the interaction through these common objects (or artefacts) of activity, not just among people or within one's mind.

\subsection{Knowledge Practices Laboratory}

One of the main goals of KP-Lab project is to research and develop relevant technologies that support trialogical learning. The essential way how to design and develop supporting collaborative technologies is a co-evolution process of researchers, technological developers and users. It is organised as follows. Trialogical learning theory, which is being developed by theoretical partners, is a fundament that needs to be transformed into real practice. This is only possible with carefully designed tools that will use together with innovative knowledge practices. We believe that one possible way how to achieve this transition from theory to practice can be the following: the pedagogies, grounded in the newly formed trialogical theory, produce scenarios and use cases that become the base for technological development.

KP-Lab technology builds on emerging technologies, such as semantic web, real-time multimedia communication, ubiquitous access using wireless devices, and interorganisational computing. There are also non-technological tools as the change laboratory (the idea is to arrange on the shopfloor a room or space in which there is a rich set of instruments for analyzing disturbances and for constructing new models for the work practice).

The multinational consortium integrates expertise from various domains, including pedagogy, psychology and engineering as well as end-users and key representatives from the corporate/business sector to provide authentic environments for research and piloting. The project involves 22 partners from 14 countries, as well as many schools, universities, companies and work places and other prospective end-users. 


\subsection{KP-Lab platform}

The KP-Lab platform is based on interoperability of the integrated tools and on a support of semantic web models and standards. It provides the technology mediation for innovative knowledge creation processes and allows the objects exchanges between applications with their specific appliance domains.

KP-Lab platform provides working environment to support cooperative and collaborative work or leaning between registered users. This environment integrates many supporting tools, e.g.

- Shared Space: a virtual collaboration space offering facilities for interacting with knowledge artefacts, knowledge process models, users and the shared space itself:

○ working with the knowledge artefacts, e.g. creating, editing, storing, sharing, commenting, annotating semantically, disseminating, discussing;

- managing the knowledge processes, e.g. creating, changing and executing process models;

- managing the shared space itself (e.g. configuring the tools available).

- Map-It: a tool that supports synchronous discussions within any group of users and semi-automatic generation of a "discussion map" and a comprehensive and organized set of discussion documentation;

- Change Laboratory: an intervention method for systematically developing work practices. It is based on the framework of developmental work research that provides reflective feedback of participant work;

- Semantic multimedia annotation tool: a tool that provides functionalities for single or collaborative annotation of multimedia clips.

One of the main purposes of such performing activities is to use tacit knowledge in the collaborative creation of shared objects of activities. Therefore, the KP-LAB platform offers facilities for discovering, managing and visualization of tacit knowledge. This knowledge in the background of the practices will be better visualized and brought forward with the new awareness features. So Awareness services will be implemented as a part of the KP-Lab platform and will work with information/data from it.

The Awareness services enable to explicate the traces through; for example, graphical views to participant's relations, patterns of sequences and actions, suggested reading and tags, etc. These features provide more explicit traces of the tacit process knowledge that is embedded in the practices of the members of the group/community, bringing it more into the open to be perceived and making it easier to consciously acknowledge and analyse it when collaboratively developing the shared objects of activity.

\section{AWARENESS SUPPORT}

\subsection{Theoretical background}

Collaborative systems require awareness support to ensure collaborators know about the activities of others in order to coordinate their work, support their collaboration, identify potential problems and prevent conflicts and misunderstandings. In order to achieve a proper interpretation on on-going and past actions in a computer-based collaborative system, one needs to take into account not only what has been the content of actions of the 
others, but also the context and semantic relations of the actions performed by the participants of a collaborative process.

One definition of awareness that is especially relevant in a domain of collaborative systems could be: "Awareness is an understanding of the activities of others which provides a context for your own activity "(Dourish and Bellotti, 1992).

Several informal definitions of distinct awareness types have been collected by Drury (Drury et al., 2002) from previous works:

- Informal awareness - the general sense of who is around and what others are up to. This is important as a prerequisite for "group structural awareness" and a baseline for informal collaboration.

- Peripheral awareness - where people know what others are doing.

- Social awareness - information about the presence and activities of people in a shared environment.

- Group structural awareness - knowledge of roles and responsibilities, their positions on an issue and process information (Begole et al, 1999).

- Conceptual awareness - knowledge about rules of activity and emerging norms of virtual collaboration (Morch et al., 2005).

- Task awareness - how to complete a common task (such as learning assignments) as well as understanding the purpose of the task.

- Workspace awareness - the up-to-the-minute knowledge a person holds about the state of others' interactions with the environment, which should reduce efforts needed to coordinate common tasks and actions relative to shared objects (Gutwin and Greenberg, 1998).

Our solution will include support of several types of awareness, e.g. we will provide status information about each user (informal awareness), present and past actions of a user (peripheral and social awareness), interaction between users and between users and environment (workspace awareness) etc.

Result information of awareness can be presented to end-users (collaborators) in a passive or active way. In the first case it is the responsibility of the user to explicitly look for the information he/she needs. In the case of active systems, the user will be notified automatically about changes in the awareness information. The first approach has the advantage that the user is in control of when and what information is displayed, avoiding information overload by these means. Nevertheless, the disadvantage is the fact that in order to monitor the change in the state of a person, the user has to access that information repeatedly.

\subsection{Log-based awareness (LBA)}

Log based (History) awareness is an asynchronous functionality that builds on persistent storage of events representing activities performed by users of various end-user tools in KP-Lab platform and based on them supports analysis and discovery of tacit knowledge from previous activities. The results can be used as inputs for the design of the tools, content and GUI adaptation for personalization.

We will provide two levels of awareness information from this module. The first level will give answers to basic questions, e.g.:

- When each member has logged in lastly?

- Recent changes: Knowing who made what changes to which object, when?

- What kinds of resources (internal or external) students have used?

- A list of all activities that the members have done (not only in actual session).

- Who is the most active/responsible user? etc. 
In cooperation with other services developed in KP-Lab (Smrz et al., 2007) and utilization of artificial intelligence techniques (e.g. various data mining techniques: clustering, association rules mining, etc.) following advanced analyses capabilities may be provided. Various statistics and graphs reflecting selected activities in the system from different points of view, present graphical view (maps) that show how the participants are related to the shared artefacts as well as to each other, discovery of interesting patterns within sequences of actions, and possibly others.

\subsection{Implementation of LBA}

LBA (Babič and Wagner, 2007) is based on generic log storage and query service to which every end-user tool will send various high-level events. These events will be defined by tools, because tools know what type of actions are important for users and may be useful to be logged and analyzed to infer knowledge from the actual working practices later on.

As an example of LBA exploitation we present communication with end-user tool called Knowledge Process Service (Babič and Paralič 2007) (also developed in our Centre). KPS is integrated as web service into the Shared space and provides a set of features and interfaces necessary for creation, management, and annotation of knowledge processes composed from various elements. Some of the KPS functions are the following:

- Create, view, update and reuse such process elements as Task or Milestone.

- Set-up description of the element - metadata. For example: name, actor, starting and ending dates for a task etc.

- Set-up relationships between process elements. For example: prerequisites mean tasks that need to be completed before actual task will start.

- Execution of a process: User can follow current state of a process by defined timeline.

- Change elements setting on the fly: User can flexibly make changes in description of relevant elements based on her/his user rights.

- Structure of the full process is visualized as Gantt chart.

This tool can generate several types of events as Modification of object metadata, Modification of object itself (create, delete) and Modification in process structure. If e.g. a user wants to be notified about changes in a particular Task (this means any change of Task properties metadata), the process is the following (see Figure 2). The user subscribes via KPS his/her interest to be notified when a particular Task changes (Subscription of Task changes in Figure 2). This subscription will be stored in the Awareness repository (Saving in database). Whenever any user makes a modification of this particular task, KPS issues an event to be logged (Modification of Task - Event) into the Awareness repository. LBA service will provide required operations and all matching subscriptions (result of Queries in Figure 2) will lead to notifications (Notification of realized event) to all their subscribers. Moreover, this event will be taken into account whenever a relevant analysis of logged events will be performed by a user or a tool (Perform History Analysis, Queries, and Provide results of Analysis in Figure 2). 


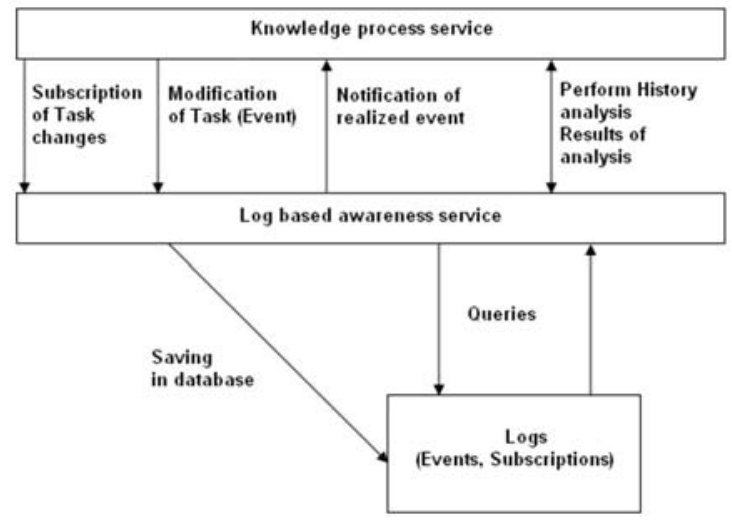

Figure 2. The schema of communication between KPS and envisaged LBA services

\section{CONCLUSION}

This paper presented one particular approach to support knowledge creation processes via awareness support within the KP-Lab collaborative environment. This functionality is required by participants of pilot courses in order to provide simple notifications as well as advanced analyses of processes. First prototype of LBA will be finished in September 2008 and will be ready for autumn field trials (pilot courses). Based on results of this test phase the LBA functionality may further be extend with e.g. additional analytical features.

\subsection{Acknowledgments}

The work presented in this paper was supported: by European Commission DG INFSO under the IST program, contract No. 27490; by the Slovak Research and Development Agency under the contract No. APVV-0391-06 and by the Slovak Grant Agency of Ministry of Education and Academy of Science of the Slovak Republic under contract No. 1/3135/06.

The KP-Lab Integrated Project is sponsored under the 6th EU Framework Programme for Research and Development. The authors are solely responsible for the content of this article. It does not represent the opinion of the KP-Lab consortium or the European Community, and the European Community is not responsible for any use that might be made of data appearing therein. 


\section{REFERENCES}

1. Babič, F., Paralič, J. "Knowledge practices Laboratory (KP-Lab) Project”. In: Znalosti 2007, VŠB-TU Ostrava, Czech Republic 2007, ISBN 978-80-248-1279-3, pp. 364-367.

2. Babič, F., Wagner, J. "Awareness service based on events logs". 2nd Workshop on Intelligent and Knowledge oriented Technologies 2007, Kosice, Slovakia. ISBN 978-80-89284-10-8, pp.106-109.

3. Begole, J., Rosson, M.B., Shaffer, C.A. Flexible Collaboration Transparency: Supporting Worker Independence in Replicated Application-Sharing Systems. ACM Transactions on Computer-Human Interaction 1999; Vol. 6: 95-132.

4. Bereiter, C., Scardamalia, M. Surpassing ourselves: An inquiry into the nature and implications of expertise. La Salle, IL: Open Court, 1993.

5. Dourish, P., Bellotti, V. "Awareness and Coordination in Shared Workspaces". In Proceedings of the AMC Conference on Computer Supported Cooperative Work (CSCW'92), Greenberg S. ed., Toronto, Canada: AMC Press, 1992, pp. 107-114.

6. Drury, J., Williams, M.G. "A framework for role based specification and evaluation of awareness support in synchronous collaborative applications". In Proceedings of the 11th International Workshops on Enabling Technologies for Collaborative Enterprises (WETICE02), Carnegie Mellon University, Pittsburgh, IEEE Computer Society Press, 2002, pp. 12-17.

7. Engeström, Y. Innovative Learning in Work Teams: Analyzing Cycles of Knowledge Creation in Practice. Cambridge, MA: Cambridge University Press, 1999.

8. Gutwin, C., Greenberg, S. "Design for individuals, design for groups: Tradeoffs between power and workspace awareness". In Proceedings of CSCW'98 ACM Conference on Computer Supported Cooperative Work, Seattle, Washington, 1998, pp. 207-216.

9. Hakkarainen, K., Paavola, S. "From monological and dialogical to trialogical approaches to learning". A paper at an international workshop "Guided Construction of Knowledge in Classrooms", February 5-8, 2007, Hebrew University, Jerusalem, 2007.

10. Mørch, A., Jondahl, S., Dolonen, J. Supporting Conceptual Awareness with Pedagogical Agents. Information Systems Frontiers, special issue on Computer Supported Collaborative Learning Requiring Immersive Presence 2005; 7(1): 39-53.

11. Nonaka, I., Takeuchi, H. The Knowledge Creating Company. Oxford University Press, New York, 1995.

12. Paavola, S., Lipponen, L., Hakkarainen, K. Models of Innovative Knowledge Communities and Three Metaphors of Learning. Review of Educational Research 2004; 74(4): 557-576.

13. Smrz, P. et al. "Specification of the SWKM Knowledge Evolution, Recommendation, and Mining services". KP-Lab public deliverable D5.3. September, 2007. 